\title{
METODE HIPNOTEACHING UNTUK ANAK SEKOLAH DASAR
}

\author{
Sunanih \\ Universitas Muhammadiyah Tasikmalaya, Jl. Tamansari km.2,5 Kota Tasikmalaya \\ Email: sunanihsyima@yahoo.co.id
}

\begin{abstract}
Abstrak
Hasil belajar peserta didik merupakan salah satu indikator dalam keberhasilan pendidikan, hasil belajar peserta didik merupakan nilai ahir dari pencapaian peseta didik dalam memehami materi yang disampaikan pada saat belajar mengajar. Banyak sekali faktor yang dapat berpengaruh pada tinggi rendahnya nilai hasil belajar peserta didik dan salah satunya adalah metode yang digunakan dalam proses pembelajaran. Dalam upaya meningkatkan hasil belajar peserta didik dapat diberikan metode hipnoteaching kepada peserta didik dan dapat diberikan pula kepada anak sekolah dasar. Pada dasarnya mengajarkan dengan beberapa metode pada anak SD itu sangat dianjurkan dimana anak pada usia ini masih tergolong masa kanak-kanak yang karakteristiknya cepat bosan sehingga metode yang diberikan harus menarik bagi anak. Metode hipnoteaching ini sangat bagus untuk diberikan kepada anak SD dimana metode-metode lama membosankan dan metode ini cukup merangsang konsentrasi bagi anak, dengan menggunakan metode ini diharapkan ada perkembangan yang baik dalam proses belajar sehingga mencapai hasil yang optimal.
\end{abstract}

\author{
Kata kunci: \\ Metode hipnoteaching, Belajar, Anak SD.
}

\begin{abstract}
Learning outcomes of students is one indicator in the success of education, the learning outcomes of students is the final value of the achievement of students in understanding the material delivered during teaching and learning. There are many factors that can influence the high and low value of student learning outcomes and one of them is the method used in the learning process. In an effort to improve student learning outcomes can be given a hypnotiching method to students and can also be given to elementary school children. Basically teaching with several methods in elementary school children is highly recommended where children at this age are still classified as childhood whose characteristics are quickly bored so the method given must be attractive to children. This hypnotiching method is very good to give to elementary school students where old methods are boring and this method is enough to stimulate concentration for children, using this method is expected to have a good development in the learning process so as to achieve optimal results.
\end{abstract}

Keywords:

Hypnotiching, Learning, Elementary School Children.

\section{A. PENDAHULUAN}

Dikalangan masyarakat banyak para ibu yang sangat hawatir anaknya tidak bisa mengikuti pelajarn di SD, obrolan kecil dengan orang tua yang mempunyai anak usia dini mereka rata-rata hawatir takut anak nya tidak bisa mengikuti materi pelajaran ketika masuk sekolah dasar. Dengan adanya kehawatiran tersebut ahirnya tidak sedikit orang tua yang memasukan les anaknya sejak dini, bahkan banyak orang tua yang memberikan berbagai les kepada anaknya, yang tidak disadari menjadi beban/tekanan buat anak karena tidak sesuai dengan masa perkembangannya.

Dengan penulisan artikel ini melalui metode hipnoteaching, semoga menjadi solusi bagi para pendidik dalam memberikan layanan pendidikan yang menyenangkan bagi anak sehingga belajar tetap merasa nyaman dan semangat. 


\section{B. PEMBAHASAN}

\section{Metode Hypnoteaching}

\section{a. Pengertian Metode Hypnoteaching}

Hypnotiching berasal dari kata hipnosos dan tteaching. Hipnosos berarti mensugesti dan teaching berarti mengajar. Jadi hypnoteaching berarti usaha untuk menghipnosis atau mensugesti anak didik supaya menjadi lebih baik dan prestasinya meningkat ( yustisia: 2012: 75). Dari pengertian diatas bisa diartikan juga bahwa hypnoteaching adalah seni berkomunikasi dengan jalan memberikan sugesti agar peserta didik menjadi lebih cerdas (Hajar, 2011 : 75). Begitu juga dengan James Braid dalam Rahmawatiningrum (2012 : 52) menyatakan tentang keyakinan akan kekuatan sugesti bahwa sugesti-sugesti dalam metode hypnoteaching selama pembelajaran berlangsung mempengaruhi hasil belajar dan motivasi peserta didik.

Dikatakan juga oleh Suwanto dalam Rahmawatiningrum (2012:13) Metode Hypnoteaching merupakan pengembangan dari teknik hipnosis. Hipnosis adalah suatu kondisi dimana perhatian menjadi sangat terpusat sehingga tingkat sugestibilitas (daya terima saran) meningkat sangat tinggi. Dilanjutkan dengan pendapat Novian Triwidia Jaya dalam Rahmawatiningrum (2012:13) menyebutkan bahwa:

"Metode Hypnoteaching adalah mengaktifkan inner motivation dan mempersuasi peserta didik. Mempersuasi peserta didik untuk nyaman dan betah dalam belajar serta dengan sugesti yang diberikan guru peserta didik akan termotivasi untuk terus menikmati belajarnya. Novian juga menambahkan bahwa metode hypnoteaching adalah perpaduan pengajaran yang melibatkan pikiran sadar (Conscious Mind) dan pikiran bawah sadar (Sub Conscious Mind)".

Dari berbagai pendapat mengenai pengertian metode hypnoteaching dapat disimpulkan bahwa metode hypnoteaching adalah metode pembelajaran yang berprinsip bahwa sugesti dapat mempengaruhi hasil belajar yang dalam penerapannya lebih ditekankan dengan penggunaan bahasa-bahasa bawah sadar.
Dengan menggunakan metode hipnotching siswa akan termotivasi karena metode ini sangat erat kaitannya degan bagaimana cara pendekatan guru yang baik kepada siswa sehingga menimbulkan minat siswa akan meningkat terhadap belajar, , karena metode ini memiliki unsur-unsur tertentu dimana guru harus berkomitmen dan konsisten dalam menggunakan metode ini adapun unsurunsur tersebut dikemukakan oleh Muhammad Noer dalam Rahmawatiningrum (2012: 13) yaitu meliputi penampilan guru, sikap yang empatik, rasa simpati, penggunaan bahasa, alat peraga, motivasa dan menguasai hati peserta didik. Hal ini bila dilaksanakan dengan baik oleh guru tentu akan sangat menyenangkan bagi peserta didik.

\section{b. Unsur-unsur Metode Hypnoteaching Muhammad Noer dalam Rahmawatiningrum (2012 : 13) menerangkan unsur-unsur Metode} hypnoteaching meliputi penampilan guru, sikap yang empatik, rasa simpati, penggunaan bahasa, peraga, motivasi dan menguasai hati peserta didik.

Penampilan guru. Penampilan yang baik akan melahirkan rasa percaya diri yang tinggi serta memiliki daya magnet yang kuat bagi peserta didik. Tingkat kepercayaan diri seseorang, tingkat kepositivan pikiran dan juga tingkat sosial kemasyarakatan dapat dilihat dari penampilan.

Sikap yang empatik. Sebagai seorang pendidik, bukan sekadar pengajar, seorang guru harus mempunyai rasa empati kepada para peserta didik, ketulusan dan kesadaran bahwa anak didik adalah menjadi tanggung jawab bersama akan menumbuhkan rasa empati. Selanjutnya rasa simpati, tugas guru yang lainnya adalah memiliki rasa simpati kepada peserta didik, tidak menganggap kecil dengan semua permasalahan peserta didik, membutukahn pendekatan dan respon dari guru dengan konsisten sehingga siswa merasa nyaman selama belajar dengan disekolah dengan sendirinya anak akan menurut kepada gurunya. Contohnya bila 
guru menganggap muridnya nakal lalu memperlakukannya tidak baik maka anak lama-lama tidak takut dengan guru dan akan melawan, karena yang mereka butuhkan pada dasarnya adalah kasih sayang seperti diungkapkan di dalan Al-Quran QS: 42:23) "itulah ( karunia) yang (dengan ituI Alloh menggembirakan hamba-hambanya yang beriman dan mengerjakan amal saleh. katakanlah: "aku tidak meminta kepadamu suatu upahpun atas seruanku kecuali kasih sayang dalam kekeluargaan". Dan siapa yang mengerjakan kebaikan akan kami tambahkan kebaikan pada kebaikannya itu. Sesungguhnya Alloh maha pengampun lagi maha mensyukuri". tetapi sebalikny jika anak dianggap nakal guru bersabar memberikan perhatian dan pendekatan serta motivasi yang baik, anak dengan sendirinya akan patuh karena merasa dihargai.

Penggunaan bahasa, guru yang baik hendaknya memiliki kosa kata dan bahasa yang baik dan enak didengar telinga, bisa menahan emosi diri, tidak mudah terpancing amarah, suka menghargai karya, potensi dan kemampuan peserta didik seperti diungkapkan dalam Surat (Annahl ayat 78) "dan Alloh mengeluarkan kamu dari perut ibumu dalam keadaan tidak mengetahui suatu apapun dan dia memberi kamu pendengaran, penglihatan dan hati agar kamu bersyukur". Guru harus mau melatih dirinya agar setiap ucapan yang dilontarkan pada anak selalu nyaman di dengar enak dilihat oleh mata itu akan membentuk hati yang sellu bersyukur pada Alloh SWT.

Peraga (bagi yang kinestetik). Salah satu unsur hipnosis dalam pembelajaran adalah peraga(pendekatan dengan gerakan) mengeluarkan ekspresi diri. Seluruh anggota badan digerakkan jika diperlukan. Tangan, kaki, mimik dan suara dieksplorasi secara maksimal dan optimal. Ketika mengajar hendaknya guru menggunakan gaya bahasa tubuh agar apa yang disampaikan semakin mengesankan. Untuk menerapkan hal ini guru harus menguasai materi yang akan disampaikan.

Motivasi peserta didik dengan cerita atau kisah. Watak dan tabiat dasar kerja pikiran adalah imajinasi dan fantasi. Cerita dan kisah merupakan kajian imajinasi. Disaat guru melihat peserta didik banyak mengalami masalah, tidak memiliki motivasi belajar dan berbagai problematika kehidupan maka guru dapat menasehati dan membimbing peserta didik tanpa menggurui.

Menguasai hati peserta didik. Belajar pengalaman di lapangan lebih mengena daripada belajar teori di kelas saja. Jika sudah bisa menguasai hati peserta didik baru bisa menguasai pikirannya.

\section{c. Cara Hipnotis Untuk Guru}

Pastikan diawal pembelajaran kondisi kelas tenang dan nyaman guru berpenampilan menyenangkan yang bisa menarik perhatian siswa. Sebagaimana dikatakan oleh Hana Pratiwi (2014: 59) penguasaan siswa di dalam kelasmerupakan elemen dasar dari suatu teknik yang di sebut truisme atau aksioma, truisme dimaksudkan sebagai penguasaan siswa di dalam kelas dengan ini guru dapat dapat menemukan cara mengantarkan siswa menuju Trance hipnoteaching. Diawal guru sebaiknya mengodisikan siswa sangat alami, sehingga siswa mudah di bimbing atau diarahkan dalam proses pembelajaran.

Pada dasarnya setiap guru memiliki potensi untuk dapat melakukan hypnoteaching, karena metode ini merupakan keterampilan yang dapat dipelajari (Hajar, 2011:113).

Berikut ini langkah-langkah untuk menumbuhkan kemampuan hypnoteaching menurut Ibnu Hajar :

1) Biasakan mengucapkan lafal-lafal dengan fasi.

2) Belajar menggunakan intonasi yang bervariasi

3) Hilangkan penggunaan kata jeda 
4) Biasakan mengatakan ide yang terlintas dalam pikiran kita, meskipun tidak nyambung.

5) Biasakan menatap tajam obyek yang diajak bicara

6) Gerakan anggota badan secara dinamis.

7) Gunakan media yang efektif

8) Biasakan menggunakan kata-kata yang memotivasi.

9) Biasakan menyampaikan pesan dengan sepenuh hati

\section{d. Langkah-langkah Metode Hypnoteaching Bagi Guru}

Ada beberapa langkah yang perlu dilakukan oleh gur dalam menerapkan metode hipnoteaching Terdapat beberapa langkah sebagaimana di kemukakan oleh yustisia ( 2012: 85) adaalah sebagai berikut:

1) Niat dan motivasi dalam diri

Segala upaya yang dikerjakan tergantung pada niat seseorang keseriusan untuk mencapai tujuan tertentu begitu jugan dengan mengajar keseriusa niat guru untuk bersungguh-sunggud itu akan memberikanhasil yang maksimal bagi siswa. Ini akan terlihat bagaimana cara dan penampilan guru mengajar.

\section{2) Pacing}

Pacing berarti menyamakan posisi, gerak tubuh dengan peserta didik. Prinsip dasar disini adalah "manusia cenderung atau lebih suka berkumpul dengan sejenisnya atau memilliki banyak kesamaan." Secara alamiah.

Contoh menyamakan gerakan yaitu dengan guru bertanya dan tidak membedakan siswa atau tidak ada diskriminasi bagi siswa. Contoh lain menyamakan ucapan dengan cara menyanyi bersama atau mengucapkan yel-yel bersama. Dengan cara sederhana dapat membuat nyaman siswa di kelas.

\section{3) Leading}

Leading dilakukan Setelah pacing, para siswa akan merasa nyaman dengan guru. Pada saat itulah hampir setiap apapun yang guru ucapkan atau tugaskan kepada siswa akan dilakukan dengan sukarela dan bahagia sehingga sesulit apapun materi, pikiran bawah sadar akan menangkap materi pelajaran dengan mudah.

\section{4) Gunakan Kata Positif}

Langkah ini merupakan langkah pendukung pacing dan leading. Penggunaan kata positif ini disesuaikan dengan cara kerja pikiran bawah sadar yang tidak mau menerima kata negatif. Kata -kata positif bila selalu didengar oleh anak akan memingkatkan motivasi belajar lebih baik lagi ( QS; annahl 78) "dan Alloh mengeluarkan kamu dari perut ibumu dalam keadaan tidak mengetahui suatu apapun, dan dia memberi kamu pendenganran, penglihatan dan hati agar kamu bersyukur.

Alloh memberi potensi pada setiap manusia berupa pendengaran,penglihatan dan hati, dimana potensi ini menjadi tugas para pendidik bagaimana anak bisa nyaman dari ucapan yang di dengar anak dan tindakan yang di lihat anak akan berpengaruh pada hati anak. Dalam pengaplikasian metode hypnoteaching hendaknya kata-kata harus bener-benar dijaga dan di sadari oleh guru.

\section{1) Berikan pujian}

Karakteristik dasar anak adalah senang di puji dan merupakan Salah satu hal yang penting dalam pembelajaran adalah reward and punishment. Pujian merupakan reward peningkatan harga diri seseorang. Pujian merupakan salah satu cara untuk membentuk konsep diri seseorang. Dengan pujian, siswa akan terdorong melakukan yang lebih dari sebelumnya.

Dalam memberikan pujian, hindari kata penghubung negatif, misalnya "tapi", "namun", "Cuma saja" dan lain sebagainya. Penggunaan kata tersebut akan membuat pujian menjadi siasia dan terkesan mengook-olok. Jika pujian digabungkan dengan kritik maka yang lebih terangkap adalah bentuk penyerangan pada harga diri orang yang dipuji. Bukannya meningkatkanharga diri, hal ini justru akan menjatuhkan peserta didik yang dipuji. Misalnya "Kamu sebetulnya adalah siswa yang pandai dan sangat membanggakan. Akan lebih membanggakan lagi kalau kamu lebih memperhatikan kerapian penampilanmu." Dalam perkataan tersebut, perisai pelindung harga diri belum sempat keluar, namun sudah ada pesan perbaikan (kritik) masuk dalam program bawah sadarnya.

2) Modelling 
Modelling adalah proses memberi tauladan atau contoh melalui ucapan dan tingkah laku yang konsisten. Hal ini sangat perlu dan menjadi kunci metode hypnoteaching. Setelah peserta didik merasa nyaman dengan guru maka diperlukan kepercayaan (trust) peserta didik kepada guru dengan perilaku guru yang konsisten melalui ucapan dan ajaran guru. Untuk mengaplikan hypnotiching bisa dilakukan dengan mudah sebagaimana diungkapkan oleh Ali Akbar Nasis ( 2012: 133) yaitu dengan menerapkan prinsipsebagai berikut:

\section{a) Agreement}

Persetujuan dari siswa anda artinya anda pas datang ke kelas harus menjadi pribadi yang sangat menarik bagi siswa dari sikap, senyum,menyapa dan berpenampilan. Bangun ikatan batin,ikatan yang kuat akansangat menentukan keberhasilan apa yang akan anda sampaikan.

b) Fokus

Untuk membawa siswa anda ke dalam kondisi hypno anda harus membimbing siswa anda untuk berkonsentrasi, kemampuan konsentrasi setiap orang berbeda-beda. Anda dapat menbawa mereka ke dalam light hypnosis untuk membuat mereka menjadi terfokus pada satu sisi saja. Pikiran terfokus dan emosi pun terkontrol.

c) Relaks

Mengajar pagi hari akan lebih efektif tetapi mengajar pada siang hari kurang efisien. Tapi hal ini bisa dikendaliakan, walau pada dararnya kemampuan seseorang ituberbeda-beda bagi yang belum merasa puas dalam mengajar yentunya bisa mempraktekan cara relaks. relaksasi ini bisa diterapkan sekalipun anda sudah mampu menguasai kelas sehingga kemampuan anda akan lebih meningkat dan hasilnya akan lebih fantastis.

Adapun reksasi bagi guru yaitu dengan a). Relaksasi tubuh dan fikiran, dengan memperhatikan etika dalam posoisi duduk dan pandangan menghadap ke depan, b). Memfokuskan diri, niat, tenang, mengendalikan diri, beberapa cabang pikiran anda, fokuskan menjadi satu kata saja "Rileks"hilangkan semua beban pikiran, c). Doa, dalam kondisi yang damai maka saat yang tepat untuk berdo'a, doa adalah sebuah komunikasi dengan Tuhan, sehingga menjadi khusyuk dan fokus..

\section{e. Prinsip dalam Pelaksanaan Hypnoteaching}

Beberapa langkah yang pelu dilakukan agar pelaksanaan pembelajaran dengan metode hypnoteaching bisa berjalan dengan efektif yaitu sebagai berikut :

1) Mengidentifikasi terlebih dahulu kebutuhan peserta didik.

2) Merencanakan pembelajaran dengan mengaitkan media hipnotis seperti suara, gambar, tulisan, gerak dan simbol-simbol.

3) Memulai mengajar sesuai dengan rencana yang telah dibuat.

4) Melakukan afirmasi.

5) Melakukan visualisasi sebagai sarana agar peserta didik dapat memproduksi gagasan sebanyak-banyaknya berkaitan dengan topik pembelajaran.

6) Melakukan evaluasi.

7) Sebelum pembelajaran berakhir, lakukan refleksi tentang sesuatu yang dialami oleh peserta didik. (Hajar, 2010 : 118)

\section{f. Keterkaitan Antara Metode Hypnoteaching dan Belajar anak SD}

Berdasarkan uraian kajian teori diatas menyimpulkan bahwa hasil belajar adalah hasil akhir dari proses kegiatan belajar mengajar yang dilihat melalui daya serap peserta didik yaitu perubahan pada kognitif, afektif dan konatif sebagai pengaruh pengalaman belajar yang dialami peserta didik terhadap materi tertentu yang telah diajarkan.

Salah satu faktor yang dapat berpengaruh terhadap tinggi rendahnya hasil belajar peserta didik adalah metode yang digunakan dalam proses pembelajaran. Dengan demikian guru harus memiliki pengetahuan yang cukup mengenai berbagai metode dapat mengembangkan metode pembelajaran sesuai dengan standar kompetensi dan kompetensi dasar yang akan dicapai agar dapat memudahkan peserta didik dalam belajar sehingga dapat mendapatkan hasil belajar yang maksimal.

Metode pembelajaran yang efektif dan aktif akan mampu meningkatkan hasil belajar peserta didik, sebaliknya jika metode yang 
digunakan adalah metode yang tidak menuntut peserta didik untuk aktif dan kreatif maka akan didapat hasil belajar yang tidak memuaskan.

Metode Hypnoteaching merupakan gabungan dari lima metode belajar yaitu quantum learning, accelerate learning, power teaching neuro linguistic programming dan hypnosis sehingga metode hypnoteaching dapat meningkatkan motivasi serta membuat peserta didik menjadi aktif dalam proses belajar.

Beberapa penelitian sebelumnya telah melihat efektifitas dari penggunaan metode hypnoteaching dalam pembelajaran. Linta Rahmawatiningrum (2012 : 53) dalam penelitianya yang berjudul "Efektivitas Penggunaan Metode Hypnoteaching Dalam Pembelajaran Matematika Kelas IV Semester II SD Islam Haji Soebandi Kecamatan Bawen Kabupaten Semarang Tahun Pelajaran 2011/2012" menyimpulkan bahwa penggunaan Metode Hypnoteaching lebih efektif dibandingkan Metode Konvensional dalam meningkatkan hasil belajar peserta didik.

Dengan demikian dari uraian kajian teori diatas dan dari hasil penelitian yang terdahulu dapat disimpulkan bahwa metode pembelajaran hypnoteching dapat meningkatkan hasil belajar peserta didik.

\section{DAFTAR PUSTAKA}

Aripin, zainal. 2014. Penelitian Pendidikan Metode dan Paradigma Baru. (Bandung: PT Remaja Rosda Karrya).

Sugiyono. 2011. Penelitian Kuantitatif Kualitatif danR\&. (Bandung Alfabeta).

Akbar, Navis, Ali. 2012. Hypnotiching Revolusi Gaya mengajar Untuk Melejitkan Prestasi. ( jogjakarta: ArRuzzmedia ).

Pertiwi, Hana. 2014. Hipnoteaching Untuk PAUD dan TK. (Jogjakarta: DIVA Press).

Yustisia. 2012. Hipnoteaching Seni Ajar Mengeksplorasi Otak Peserta Didik
. ( Jogjakarta: Ar-Ruzzmedia ).

Hajar, Ibnu. 2012. Hipnoteaching memaksimalkan hasil proses belajarMengajar dengan Hipnoterapi. ( Jogjakarta: DIVA Press ).

Abbas, N, et.al. (2011). Pendidikan Agama Islam untuk Sekolah Dasar Kelas V. ( Jakarta: Pusat Perbukuan Kementrian Pendidikan Nasional).

Anonymous, (2013). Hypnoteaching Menggunakan Rangkaian Kata Sugesti Pada Proses Pembelajaran Cemerlang. ( Jakarta: Komunitas Guru Kreatif (Creativity Teaching Community)).

Anonymous, (2006). Standar Isi untuk Satuan Pendidikan Dasar dan Menengah Standar Kompetensi dan Kompetensi Dasar SD/MI. ( Jakarta: Badan Standar Nasional Pendidikan).

Arikunto, S, (2009), Dasar-dasar Evaluasi Pendidikan, Jakarta, PT. Bumi Aksara

Aziz, A. (2009). Pengertian dan Tujuan Pendidikan Agama Islam, tersedia: (http://islamblogku.blogspot.com/2009 /07/pengertian-dan-tujuan-pendidikanagama_1274.html [5 Mei 2014]).

Diyana, M,Y. (2008). Pengaruh Metode Ceramah Terhadap Prestasi Belajar Pendidikan Agama Islam di Kelas VIII SMP Islam Al-Asmaniyah Kelapa Dua Kabupaten Tangerang. (Tangerang: Sekolah Tinggi Agama Islam Muhammadiyah)

Djamarah, S.B, Zain, A. (2010). Strategi Belajar Mengajar. ( Jakarta, PT. Rineka Cipta).

Mustofa, Z, koswara. ( 2011). Pendidikan Agama Islam Untuk SD Ke;las V. ( Jakarta: Pusat perbukuan kementrian Pendidikan nasional). 
Rahmawatiningrum, L, (2012). Efektivitas Penggunaan Metode Hypnoteaching Dalam Pembelajaran Matematika Kelas IV Semester II SD Islam Haji Soebandi Kecamatan Bawen Kabupaten Semarang Tahun Pelajaran 2011/2012. (Salatiga:
Fakultas Keguruan dan Ilmu Pendidikan Universitas Kristen Satya Wacana).

Rusman, (2010). Model-Model Pembelajaran Mengembangkan Profesionalisme Guru. (Jakarta: PT. Raja Grafindo Persada). 